EESTI NSV TEADUSTE AKADEEMIA TOIMETISED. XV KÖIDE

FUUSIKA-MATEMAATIKA- JA TEHNIKATEADUSTE SEERIA. 1966, NR. 4

ИЗВЕСТИЯ АКАДЕМИИ НАУК ЭСТОНСКОН ССР. ТОМ ХV

СЕРИЯ ФИЗИКО-МАТЕМАТИЧЕСКИХ И ТЕХНИЧЕСКИХ НАУК. 1966, № 4

Ф. KJEMEHT.

\title{
О РАБОТАХ ТАРТУСКИХ ФИЗИКОВ ПО ИЗУЧЕНИЮ ЛЮМИНЕСЦЕНЦИИ ТВЕРДЫХ ТЕЛ *
}

В июле 1965 г. Советская Эстония отметила свое 25-летие. Ровно половина этого срока прошла с момента, когда старший лаборант (а сейчас - заведующий сектором) Я. Кирс, аспирант (ныне - заведующий кафедрой ТГУ) К.-С. Ребане и младший научный сотрудник (сейчас старший научный сотрудник) А. Малынева с участием автора этих строк в конце 1952 г. приступили в Тарту к работе в области люминесценции, положив этим начало направлению, охватывающему ныне большой коллектив в несколько десятков человек (в том числе 3 доктора и 16 кандидатов наук). К настоящему времени этим коллективом опубликовано около 425 исследований, краткому обзору которых и посвящена данная статья.

Работы тартуского коллектива характеризуются несколькими особенностями.

Люмйнесценция как физическое явление представляла для нас не только предмет изучения, но и метод исследования широкого круга вопросов физики твердого тела. Свет, излучаемый люминесцирующим телом, является богатым источником информации об энергетических состояниях и характере процессов в излучающем веществе. Наши исследования оптических явлений в кристаллах тесно переплетались с изучением явлений электрических, с изучением структуры твердого тела.

Основные работы тартуского коллектива велись экспериментальными методами. Вместе с тем в Тарту возникла также значительная группа теоретиков, возглавляемая членом-корреспондентом АН ЭССР доктором физико-математических наук К. Ребане, которая работала в тесном контакте с экспериментаторами. Наконец, если главное внимание тартуских физиков было посвящено фундаментальным исследованиям общенаучного значения, то наряду с этим велись также разработки прикладного характера, причем работы обоих направлений были между собой органически связаны.

Главным объектом наших исследований были щелочногалоидные кристаллы как простейшая модель твердого тела вообше. Лишь часть наших работ была посвящена также другим объектам. Поэтому в рамках физики твердого тела центральное внимание в тартуских работах уделялось физике ионных кристаллов.

Наиболее важная часть работ теоретического направления освещена

* Статья представляет собой изложение доклада, прочитанного на сессии Отде левия физико-математических наук АН ЭССР 24 июня 1965 г 
в докладе К. Ребане на юбилейной сессии АН ЭССР в июне 1965 г. [1]. Это избавляет нас от необходимости излагать результаты этих работ. Отметим лишь, что в последнее время К. Ребане и возглавляемая им группа сконцентрировала свое внимание на вопросах динамики кристаллической решетки и занялась изучением колебательной структуры спектров кристаллов, содержащих примеси. Разработан тақ называемый метод моментов, позволивший получить исключительно интересные результаты и понять многие стороны ранее неясных вопросов [2,3].

Другое направление теоретических исследований было представлено Н. Кристофелем, занимавшимся квантово-механическим расчетом электронных энергетических состояний частиц, находящихся в поле кристаллической решетки. Сопоставление результатсв подобных расчетов с данными экспериментальных йследований позволяет проверять правильность принятых нами моделей явления [4-7].

Самая значительная часть экспериментальных работ тартуского коллектива уже ряд лет возглавляется членом-корреспондентом АН ЭССР доктором физико-математических наук Ч. Лущиком. Поскольку эти работы также освещены уже в докладе Ч. Лущика на сессии АН ЭССР в сентябре 1964 г. [8], мы ограничимся и в их отношении лишь обшей характеристикой. Ч. Лущик и руководимая им большая группа молодых сотрудников в самом широком аспекте занимались проблемой электронных возбуждений и характером электронных процессов в ионных кристаллах $[9,10]$. Изучались оптические спектры активированных кристаллов, кинетика и механизм рекомбинационных процессов. Наряду с оптическим возбуждением изучалась люминесценция при возбуждении электронным пучком, а также радиолюминесценция. В связи с последней рассматривались вопросы генерации радиационных дефектов. Значительное внимание уделялось разработке методов получения активированных кристаллов и новых методов экспериментальных исследований.

Одно из основных направлений работ таргуского коллектива - изучение связи кристаллической структуры и спектральных свойств люминофоров, тесно связанное с изучением природы центров свечения. Начатое нами еще в Ленинграде совместно с Н. Ивановой [11, 12], это направление успешно продолжалось в. Тарту в работах А. Паэ $\left[{ }^{13,14}\right]$, Р. Гиндиной $\left[{ }^{15}\right]$, Т. Абдусадыкова $\left[{ }^{16}\right]$, А. Хаава $\left[{ }^{17}\right]$. Рентгенографические методы были дополнены электронографическими и электронномикроскопическими, а в последнее время также изучением электронного парамагнитного резонанса - Ю. Халдре [18]. Наряду со щелочногалоидными фосфорами эти исследования велись и на аммонийно-галоидных фосфорах, самая способность которых светиться была обнаружена также в нашем коллективе [19]. Установлен ряд фактов резкого изменения спектров в точке полиморфного перехода от одной кристаллической модификации данного вещества к другой, что прямо опровергает точку зрения некоторых физиков о сильной изолированности центра свечения от основной решетки.

А. Паэ $\left[{ }^{13}\right]$ установил интересный факт значительной разности стоксовых потерь в фосфоре одного и того же состава при переходе основания от решетки типа $\mathrm{CsCl}$ к решетке типа $\mathrm{NaCl}$.

Для системы $\mathrm{NH}_{4} \mathrm{~J}+\mathrm{TlJ}$ детально изучена диаграмма состояний и люминесцентные характеристики в разных состояниях [13].

Ряд исследований был посвящен явлениям, связанным с распадом твердых растворов. В работе с Р. Гиндиной было установлено, что раздробление щелочногалоидных фосфоров, являющихся пересыщенными 
твердыми растворами, ведет к их распаду, что объясняет некоторые случаи так называемого «гасящего трибоэффекта» $\left[{ }^{20}\right]$.

А. Хаав [17] исследсвал рентгенографически явление распада некоторых твердых растворов на основе $\mathrm{NaCl}$ и показал ошибочность заключений $M$. Шамовского о поверхностной природе центров свечения в этих фосфорах.

В работах Т. Абдусадыкова [16] изучалось влияние пластической деформации и других искажений решетки на спектры кристаллофосфоров. Был получен обильный материал, подтверждающий, что длинноволновые полосы щелочногалоидных фосфоров обязаны образованиям с участием дефектов основной решетки.

В работе Р. Гиндиной, А. Маарооз и А. Хаава [21] химическим, рентгенографическим и абсорбционным методами была определена концентрация активатора в $\mathrm{KCl}$-Tl. Совпадсние полученных значений концентраций явилось еше одним подтверждением развиваемого нашим коллективом представления о природе центров свечения в щелочногалоидных кристаллофосфорах. Непосредственно этому вопросу были посвящены работы $[22-24]$.

K исследованиям структурного направления относятся также работь, проведенные с участием Л. Тейсс-Лембра [25] по изучению особенностей структуры фосфоров со смешанными основаниями (типа $\mathrm{KCl} \cdot \mathrm{KBr}$ или $\mathrm{NaCl} \cdot \mathrm{KCl})$. Удалось обнаружить системы спектральных полос, соответствующих разным изоструктурам в смешанных кристаллах, а также получить поляризованное излучение в системах с нарушенной кубической симметрией.

Близки к работам структурного направления исследования по влиянию высокого давления на спектры кристаллофосфоров, выполнявшиеся Я. Кирсом и его сотрудниками $\left[{ }^{26-29}\right]$. До этих работ влияние параметров решетки на спектральные свойства кристаллов изучалось лишь на гомологических рядах веществ, отличающихся не только параметрами решетки, но и химическим составом. Всестороннее сжатие кристалла при высоком давлении позволяет изменять параметры решетки без изменения химического состава и температуры кристалла. Было установлено, что всестороннее сжатие вызывает заметное смещение спектров причем в использованном диапазоне давлений (до 6 тыс. атм) величина смещения приблизительно линейно зависит от величины давления Направление сдвигов спектров излучения не зависит от вещества основания, а определяется свойствами частиц активатора. Была обнаружена также связь между упругими и электронно-энергетическими характеристиками кристаллов. Полученные результаты рассмотрены теоретически с учетом разной сжимаемости центров свечения в основном и возбужденном состояниях [30] и представляют интерес для выяснения зависимости различных физических характеристик кристаллов от величнны межионных расстояний и для понимания спектральных закономерностей в гомологических рядах и в смешанных кристаллах. Особый интерес представляет возможность путем всестороннего сжатия осуществлять полиморфные переходы в кристаллах без изменения их темнературы и изучать таким образом зависимость спектральных характеристик кристаллофосфора от типа кристаллической структуры.

Вся эта большая группа работ по связи структуры кристаллов и их спектральных свойств позволила поставить вопрос о люминесцентных методах структурного и физико-химического анализа [ $\left.{ }^{31}\right]$.

Другое направление работ тартуского коллектива, осуществлявшееся в основном K.-С. Ребане $\left[{ }^{32-35}\right]$, посвящено изучению влияния инфра- 
красной радиации на процессы люминесценции. На фосфорах типа ZnS получен ряд интересных результатов, установлена связь инфракрасных полос тушения с полосами термовысвечивания, обнаружено, что кинетика инфракрасных процессов имеет бимолекулярный характер. Выявилась зависимость инфракрасного тушения от температуры (в одной из полос при низких температурах наблюдается только вспышка без тушения). Проведено измерение локального разогрева центров по расширению полос при инфракрасном тушении. Этот разогрев оказался меньше, чем необходимо для температурного тушения, что опровергает одну из теорий инфракрасного тушения (Ленарда-Риля). Обнаружено существование особых центров тушения. Выявлена связь коэффициента тушения с постоянной решетки, с концентрацией активатора, со степенью измельченности кристаллофосфора.

Ряд исследований инфракрасных эффектов в щелочногалоидных кристаллофосфорах провел П. Хелленурме [36].

$\mathrm{K}$ явлениям инфракрасного тушения близко примыкают температурное и концентрационное тушение люминесценции. Л. Ребане изучала взаимную связь концентрационного и температурного тушения и сделала важный шаг в понимании этого вопроса, учтя взаимодействие и передачу энергии между центрами свечения разного типа [ $\left.{ }^{37}\right]$.

Отдельный цикл составляют работы, в которых изучалась связь оптических (люминесцентных) и электрических (полупроводниковых) свойств кристаллов. Ряд исследований в этом направлении провел на сульфидных фосфорах У. Нымм [38-40]. Разрабатывалась методика электрических исследований (усовершенствован конденсаторный метод, применялся метод динамического конденсатора). Изучались фотопроводимость, фотоэлектрическая поляризация и фотодиэлектрический эффект. Определялась природа носителей тока в фосфорах. Установлен интересный факт связи инфракрасного тушения люминесценции и проводимости.

Изучение электрических явлений в диэлектрических кристаллах, которыми до последнего времени интересовались главным образом оптнки, представляется перспективным в связи с возникновением новой отрасли техники - диэлехтрической электроники. С целью расширения исследований электрических явлений в кристаллах в Институте физики и астрономии АН ЭССР создан сектор физики полупроводников (руководитель - Я. Кирс), а в Тартуском университете - проблемная лаборатория полупроводников и электролюминесценции (руководитель K.-С. Ребане). В обоих учреждениях электрические явления продолжают изучаться в тесной связи с оптическими. Работы по электролюминесценции ведутся в основном в направлении повышения эффективности электролюминесцирующих конденсаторов за счет более глубокого изучения природы пронсходящих в них процессов.

Дальнейшее развитие получили в тартуском коллективе также работы по сублимат-фосфорам (А. Малышева, А. Хаав и др.). Решались технологические задачи - распространение методики сублимации, разработанной первоначально для щелочногалоидных фосфоров, на новые классы объектов (галоидные соли металлов 2-й группы и сульфид цинка). Методика сублимации использовалась для получения многослойных люминесцирующих экранов, позволяющих преобразовывать ультрафиолетовое излучение разных областей спектра в видимое свечение разных цветов [41-45].

Вместе с тем методика сублимации применялась для более полного изучения некоторых физических свойств кристаллов, в том числе спектров поглощения люминесцирующих систем и образующих их компонен- 
тов. Велось также изучение физических процессов, ведущих к образованию сублимат-фосфоров. В частности А. Хаав исследовал электронографически процессы кристаллизации сублимированных слоев и влияние на эти процессы газов и паров [ $\left.{ }^{46}\right]$. Изучались процессы адгезии сублимированных слоев на подложках разного состава и при разных температурах [47].

Во всех этих работах само явление люминесценции, как и явление образования люминесцирующего слоя, все в большей мере превращалось в метод изучения физических проблем весьма обшего характера.

Отметим, наконец, работы чисто химического направления по изготовлению навых люминесцирующих составов и по методам получения «люминесцентно чистых» исходных препаратов. Эти работы были начаты А. Москвиным на кафедре аналитической химии ТГУ и продолжаются в настоящее время $M$. Аллсалу $[48,49]$.

В заключение хотелось бы отметить некоторые организационные особенности нашей работы, содействовавшие ее успеху и тому признанию, которое она получила в СССР и за рубежом.

Вся наша работа велась на основе тесного сотрудничества высшего учебного заведения (Тартуского университета) и научно-исследовательского учреждения (Института физики и астрономии Академии наук ЭССР). Институт располагал материальной базой (оборудованием, штатами) и возможностью заниматься научной работой без отрыва на чрезмерную педагогическую работу, университет располагал неиссякаемым резервом молодых кадров в лице студенчества. Участие сотрудников института в учебной работе университета обеспечивало им постоянный контакт со студентами, позволяло вовлекать их в научную работу еще на студенческой скамье по тематике института (курсовые, дипломные работы, производственная практика), создавало возможность систематического отбора лучших студентов на работу в институт. Это обеспечивало здоровый органический рост института по мере появления специально подготовленных кадров, пополняемых, притом, за счет персонально отобранных действительно одаренных лиц.

С другой стороны, преподаватели и студенты университета имели расширенные возможности работать научно, пользуясь также базой института. Был создан руководящий центр, объединявший ведущих физиков университета и института, координировавший тематику, использование кадров и материальной базы.

Систематически работал объединенный научный семинар, проведший к настоящему времени около 350 занятий.

В издании института («Труды Института физики и астрономии АН ЭССР. Исследования по люминесценции») регулярно печатались работы как сотрудников института, так и преподавателей университета. Вышедшие до сего времени 20 номеров этого издания являются единственным регулярно выходящим специализированным органом по люминесценции не только в нашей стране, но и за рубежом.

Институт и университет совместно положили начало общесоюзным научным совещаниям по физике ионных кристаллов (1-е - в Тарту, 2-е - в Риге, 3-е - во Львове, предстоит 4-е - в Тбилиси) и сейчас составляют один из основных центров, направляющих эту работу в CCCP.

Быстрое и успешное развитие в Тарту научных исследований по физике, почти полностью отсутствовавших в буржуазной Эстонии, еще раз демонстрирует, какие широкие возможности для развития науки возникли с восстановлением Советской власти в Эстонии, 


\section{Л ИТЕ РА Т У РА}

1. Ре 6 а не К. К., Материалы юбилейной сессии АН ЭССР, посвященной 25-й годовщине Советской Эстонии, Таллин, 1966.

2. Ребане К. К., Метод моментов и теория колебательной структуры спектров примесных кристаллов, Дисс. докт. физ.-матем. наук, Тарту, 1964.

3. Кристофель Н. Н., Ребане К. К., Трифонов Е. Д.. Хижняков В. В., Изв. АН ЭССР. Сер. физ.-матем. и техн. наук, 13, 27 (1964).

4. Кристо фель Н. Н., Квантовомеханический расчет адиабатических потенциа. лов и некоторых свойств центров люминесценции в щелочногалоидных кристаллофосфорах, Дисс. канд. физ.-матем. наук, Тарту, 1959.

5. Кристофель Н. Н.. Тр. ИФА АН ЭССР, № 10, 3 (1959); № 11, 180 (1960); Оптика и спектр., 9, 615 (1960).

6. А б аренков И. В., Кристофель Н. Н., Петрашень М. И., Оптика и спектр., 10, 487 (1961).

7. Кри ст о фель Н. Н., За в т Г. С., ФТТ, 5, 1279 (1963); Оптика и спектр., 16. 256 (1964).

8. Л ущик Ч. Б., Тр. ИФА АН ЭССР, № 31, 19 (1966).

9. Лущик Ч Б., Физические процессы в щелочногалоидных кристаллофосфорах. Дисс. докт. физ.-матем. наук, Тарту, 1962.

10. Л ущик Ч. Б., Изв. АН СССР. Сер. физич., 29, № 1, 10 (1965)

11. К лемент Ф. Д., Иванова Н. И., ЖФХ, 25, вып. 7,869 (1951)

12. И в а нов а Н. И., Қ вопросу о влиянии кристаллохимических факторов на излучение кристаллофосфороз. Дисс. канд. физ.-матем. наук, Ленинград, 1952.

13. Паэ А. Я., Структура и спектры аммонийно-галоидных кристаллофосфоров. Дисс. канд. физ.-матем. наук, Тарту, 1960.

14. П а э А. Я., У й бо Л. Я., Изв. АН СССР. Сер. физич., 24, № 3, 347 (1961).

15. Гиндина Р. И., Исследование микроструктуры центров люминесценции в щелочногалоидных кристаллах, Дисс. канд. физ.-матем. наук, Тарту, 1963.

16. А бдус адыков Т. А., Исследование центров люминесценции в щелочногалоидных фосфорах с большими концентрациями активатора и микродефектов оєновной решетки, Дисс. канд. физ.-матем. наук, Тарту, 1961.

17. $\mathrm{X}$ а а в А. А., Тр ИФА АН ЭССР, № 26, 79 (1964); № 28, 54 (1964).

18 Пунг Н. А., Х а лдре Ю. Ю., Тр. ИФА АН ЭССР, № 31, 133 (1966)

19. Клемент Ф. Д., Изв. АН СССР. Сер. физич., 15, 651 (1951).

20. Клемент Ф. Д., Гинд ин а Р. И., Тр. ИФА АН ЭССР, № 4, 3 (1956); Изв. АН СССР. Сер. физич., 21, № 5, 748 (1957).

21. Гиндии а Р. И., М а арооз А. А., Х а а в А. А., Тр. ИФА АН ЭССР, № 30 . $16(1964)$.

22. Клемент Ф. Д., Тр. ИФА АН ЭССР, № 1, 3 (1955)

23:- Клемент Ф. Д., Материалы VII совещания по люминесценции, Тарту, 1959. стр. 3 .

24. К лем ен т Ф. Д., Изв. АН СССР. Сер. физич., 29, № 1, 86 (1965).

25. К лемен т Ф. Д., Тейсс Л. А., Тр. ИФА АН ЭССР, № 14, 76 (1961); Изв. АН СССР. Сер. физ. 25, № 1, 28 (1961); Сб. Физика щелочногалоидных кристаллов, Рига, 1962, стр. 140.

26. Кирс Я. Я., Влияние высокого давления на спектры- излучения некоторых кристаллофосфоров, Дисс. канд. физ.-матем. наук, Тарту, 1957; Изв. АН СССР. Сер. физич., 21, № 5, 754 (1957); Тр. ИФА АН ЭССР, № 14, 135 (1961).

27. К и р с Я. Я., Л а йс а а р А. И., Тр. ИФА АН ЭССР, № 10, 51 (1959); № 12 , 42 (1960); № 18, 23 (1962); Материалы VII совещания по люминесценции, Тарту, 1959, стр. 59; Изв. АН СССР. Сер. физич., 25, № 3, 366 (1961).

28. К и рс Я. Я., Н и йлиск А. И., Тр. ИФА АН ЭССР, № 18, 36 (1962).

29. Л а й с а а р А. И., Тр. ИФА АН ЭССР, № 26, 57 (1964).

30. Кристофель Н. Н., Тр. ИФА АН ЭССР, № 10, 43 (1959)

31. Клемен т Ф. Д., Тр. ИФА АН ЭССР, № 7, 3 (1958).

32. Р е бане К.-С. К., Исследование инфракрасного тушения в фосфорах типа сульфида цинка, Дисс. канд. физ.-матем. наук, Тарту, 1955; Тр. ИФА АН ЭССР, № 4. 81 (1956); № 6, 126 (1957); № 7, 357 (1958); № 8,105 (1958); № 18,143 
(1962); № 26, 194 (1964); Изв. АН СССР. Сер. физич., 21, 546 (1957); 23, 1296. (1959); Матерналы V совешания по люминесценции, Тарту, 1957, стр. 166; Оптика и спектр., 4, 212 (1958); Eesti Loodus, № 2, 75 (1958).

33. Р еб не К.-С., С акаринен Э., Оптика и спектр., 8, 545 (1960).

34. Ребане К.-С. К., Рутта С В. И., Ж. прикл. спектр., 2, № 4, 350 (1965).

35. Ребане К.-С. К., Т альвисте Э. К., Тр. ИФА АН ЭССР, № 15, 161, 172 (1961); № 23, 200 (1963)

36. Х лл ленурм е П. А., Фотостимулированная люминесценция шелочногалоидных кристаллофосфоров, Дисс. канд. физ.-матем. наук, Тарту, 1961.

37. Ребане Л. А., Взаимная связь коншентрационного и температурного тушения люминесценции в некоторых шелочногалондных кристаллофосфорах, Дисс. канд. физ.-матем. наук, Тарту, 1962; Тр. ИФА АН ЭССР, № 28, 45 (1964).

38. Н ы м У. Х., Комплексное исследование фотоэлектрических и люминесцентных явлений в кристаллофосфорах типа ZnS, Дисс. канд. физ.-матем. наук, Тарту, 1963; Изв. АН СССР. Сер. физич., 23, № 11, 1286 (1959).

39. Н ы м У. Х., У й 6 о Л. Я., Изв. АН СССР. Сер. физич., 21, № 5, 648 (1957).

40. Н ы м м У. Х., Р а м м о И. Х., Тр. ИФА АН ЭССР, № 21, 284 (1962).

41. К лемент Ф. Д., Изв. АН ЭССР. Сер. техн. и физ.-матем. наук, 5 , № $1,3(1956)$. Оптика и спектр., 1,571 (1956).

42. $М$ а лы ше в а А. $Ф$., О опектральных свойствах некоторых галоидных суб́лиматфосфоров, Дисс. канд. физ.-матем. наук, Тарту, 1959; Тр. ИФА АН ЭССР, № 11. 29 (1960); № 12, $111(1960)$.

43. М алышев а А. Ф., Иыги Х. Р., Тр. ИФА АН ЭССР, № 17, 105 (1961).

44. М алышев а А. Ф., Егоров а Л. С., Тр. КФА АН ЭССР, № 21,72 (1962),

45. М алышев а А. Ф., К алде р К. А., Тр. ИФА АН ЭССР, № 30, 68 (19044).

46. Х а а в А. А., Тр. ИФА АН ЭССР, № 14, 111 (1961); Изв. АН СССР. Сер. физич., 25, № 3,356 (1961).

47. И г и Х. Р., Тр. ИФА АН ЭССР, № 30, 57 (1964)

48. А ллсалу М.-Л. Ю., Люминесцентныс сьойства окислов сурьмы и некоторых их производных, Дисс. канд. хим. наук, Тарту, 1962.

49. А ллсал у М.-Л. Ю., К у р м В. Э., Молд а у М. Э., Тр. ИФА АН ЭССР, № 28 , 61 (1964)

\section{Тартуский государственный университет}

Поступила в редакцию 29/III 1966 